\title{
TEMPRANOS ECOS DE LA REFORMA UNIVERSITARIA COR- DOBESA ENTRE LOS JURISTAS BRASILEÑOS*
}

\section{FIRST ECHOES OF THE CORDOBAN UNIVERSITY REFORM AMONG BRAZILIAN JURISTS}

\author{
EZEQUiEl ABÁSOLO**
}

\begin{abstract}
Invocada más de una vez la genérica proyección del movimiento reformista argentino de 1918 en el ámbito continental, y hoy ponderada como un hito significativo en la trayectoria de la enseñanza universitaria brasileña, lo cierto es que a la fecha no se sabe de manera precisa cuándo, cómo, en qué contexto y por qué motivos los episodios cordobeses repercutieron entre los juristas del Brasil. Utilizando fuentes parlamentarias, periodísticas y doctrinarias directas, y avanzando en un marco teórico ya planteado con anterioridad [cfr. Abásolo, E., La cultura jurídica latinoamericana y la circulación de ideas durante la primera mitad del siglo XX (2014)], este artículo pretende resolver provisoriamente los referidos interrogantes, centrándose en la evaluación del papel ejercido durante la década de 1920 por destacados juristas brasileños, quienes desde comienzos del siglo $\mathrm{XX}$ se entusiasmaban con las soluciones y los productos normativos oriundos de la Argentina.
\end{abstract}

PALABRAS CLAVE: Pensamiento jurídico. Juristas. Circulación de ideas. Argentina. Reforma universitaria.

\begin{abstract}
Invoked more than once the generic projection of the Argentine reform movement of 1918 in the continental scope, and now considered as a significant milestone in the trajectory of Brazilian university teaching. Is not know for sure the precise date, as well the context, how, when and which reasons took to the episode of cordoban rephercussions among the jurists of Brazil. By using parliamentary sources, journalists and direct doctrinaires advancing in a theoretical framework previously demonstrated (according to Abásolo, E., La cultura jurídica latino-americana y la circulación de ideas durante la primera mitad del siglo XX (2014)). This article intends to resolve these questions provisionally, focusing on the evaluation of the role played during the 1920s by prominent Brazilian jurists who have been enthusiastic about solutions and normative products from Argentina since the beginning of the 20th century.
\end{abstract}

KEYWORDS: Legal thinking. Jurists. Circulation of ideas. Argentina. University reform.

SUMÁRIO: Introducción. Primeras impresiones brasileñas sobre la reforma universitaria cordobesa. Las universidades argentinas, en la mira de los juristas brasileños. Rastreo de las vías de circulación de la experiencia cordobesa en el Brasil. Un problema local, en la raíz de la difusión en el Brasil de la reforma universitaria argentina. Consideraciones finales.

* Este trabajo se integra al proyecto IUS-Universidad Católica Argentina "Experiencias de reforma en el derecho privado argentino y latinoamericano, entre el agotamiento de la cultura jurídica del ius commune y el cuestionamiento de la codificación inicial”.

* Doctor en Derecho (Universidad de Buenos Aires). Doctor en Ciencias Políticas (Universidad Católica Argentina). Vinculación institucional: Universidad Católica Argentina.

E-mail: ezequielabasolo@gmail.com. 


\section{INTRODUCCIÓN}

Invocada más de una vez la genérica proyección del movimiento reformista de 1918 en el ámbito continental iberoamericano ${ }^{1}$, su impacto viene siendo considerado más o menos pacíficamente como un hito significativo en la trayectoria de la educación universitaria brasileña, aunque algo desfasado de lo acontecido en el entorno regional ${ }^{2}$. Empero, en algún reciente estudio se ha advertido que "las viejas banderas de la Reforma Universitaria de Córdoba" sólo "llegaron tardíamente al Brasil, por intermedio de UNE [Unión Nacional de Estudiantes], al iniciarse los años de 1960"3. La bibliografía "clásica" dedicada al asunto no ha profundizado demasiado en el tema, más allá de algunos comentarios generales -no siempre fundamentados de la manera adecuada ${ }^{4}$, y de la reproducción, por parte del líder reformista argentino Gabriel del Mazo, de un reducido elenco de piezas documentales, aisladas de su contexto y con algunas deficiencias en su reproducción y catalogación ${ }^{5}$.

1 Al respecto, pueden verse, entre otros, TORRES, Carlos Alberto. La universidad latinoamericana: de la reforma de 1918 al cambio estructural en los noventa. Revista Mexicana de Investigación Educativa, México, vol. 4, núm. 8 (julio-diciembre de 1999), p. 347, quien afirma que "la reforma universitaria de Córdoba en 1918 fue un hecho crucial en la transformación de esta institución en Latinoamérica en este siglo”. PASTRANA RODRIGUEZ, Eduardo. La reforma universitaria, el movimiento de Córdoba y sus repercusiones en Colombia. Educere. Foro Universitario (Cali, Colombia), año 12, núm. 41 (abril-junio de 2008), p. 318. BIAGINI, Hugo. E. La reforma universitaria. Antecedentes y consecuentes. Buenos Aires: Leviatán, 2000, p. 60 y sigs.

2 BUCHBINDER, Pablo. Pensar la reforma universitaria cien años después. Revista Iberoamericana de Educación Superior (México), UNAM-IISUE/Universia, vol. ix, núm. 25, p. 89.

3 TRINDADE, Hélgio. A República em tempos de reforma: o desafio do governo Lula. Educaçao \& Sociedade (Campinas), vol. 25, núm 88 (octubre de 2004), p. 828.

4 Me viene a la memoria que, salvo una interpretación personal de las singulares características del reformismo universitario brasileño que no alcanza a veinte renglones, en su Estudiantes y política en América Latina. El proceso de la reforma Universitaria (1918-1938) [México: Siglo XXI, 1978], al ocuparse del Brasil Juan Carlos Portantiero se reduce a reproducir un manifiesto carioca de noviembre de 1929, que ya había sido incorporado a la segunda edición del volumen II de La Reforma Universitaria, de Gabriel del Mazo (1941), p. 203 y sigs.

5 De las doce piezas documentales que Gabriel del Mazo reproduce como "brasileñas" en el volumen II de la segunda edición de su obra citada en la nota anterior -La Plata, Centro de Estudiantes de Ingeniería, 1941-, cinco son escritas por argentinos: una es de autoría del mismo del Mazo; otra debida a la pluma del médico reformista de extracción radical Nicolás Romano, si bien publicada en el Brasil -en O Jornal de 12 de octubre de 1928, integrando la edición conmemorativa por el Centenario de la Paz argentino-brasileña-, bajo el título "La reforma universitaria argentina"; y tres más, redactadas por agrupaciones de estudiantes universitarios. De las siete restantes, hay una declaración que por su contenido y detalles parece redactada por un argentino, para ser reproducida en portugués en el Brasil -me refiero a "Córdoba en peligro"-; y otras tres, en rigor de verdad, resultan expresión de un mismo grupo intelectual, por lo cual no necesariamente reflejan un ambiente, sino la expresión de un grupo reducido. Me refiero al liderado por el profesor de medicina Pedro Lobo, nucleado en torno de la revista Folha Académica. Corresponde señalar, además, que en el ya recordado "Manifiesto de Estudiantes" de 1929, se cita erróneamente el nombre del entonces estudiante Djacir Menezes, tornando difícil que el público no iniciado comprenda que se trata de la misma persona que cuatro décadas 
Lo cierto es que a la fecha no se sabe de manera precisa cuándo, cómo, en qué contexto y por qué motivos los episodios cordobeses -de honda relevancia para definir entonces los estándares de formación de los futuros expertos universitarios en derecho- repercutieron entre los juristas brasileños. Tampoco cuál fue la interpretación o "lectura" a la cual estos episodios argentinos quedaron sometidos en el Brasil. Utilizando fuentes parlamentarias, periodísticas y doctrinarias directas, y avanzando en un marco teórico ya planteado con anterioridad, esta colaboración intenta resolver provisoriamente los referidos interrogantes, de acuerdo con la información que se ha conseguido reunir hasta el momento ${ }^{6}$. Como queda dicho, en el examen de este concreto caso de circulación internacional de ideas y de propuestas pedagógico-jurídicas aplico los criterios que presenté en otro lugar de manera más desarrollada. En síntesis, se trata de considerarlo expresión de una cultura jurídica, y no de una mera manifestación normativa. Vale decir, en tanto episodio de circulación horizontal de reflexiones y propuestas entre comunidades jurídicas periféricas, propio de un modo de producción intelectual específico, signado por el dominio de ciertas ideas y creencias arraigadas en torno a la manera de reflexionar sobre el derecho y de practicarlo profesionalmente.

\section{PRIMERAS IMPRESIONES BRASILEÑAS SOBRE LA REFORMA UNI- VERSITARIA CORDOBESA}

Inicialmente, el conocimiento que los brasileños tuvieron de las experiencias cordobesas provino de las noticias reproducidas por la prensa periódica de Rio de Janeiro -entonces capital federal del Brasil-, las cuales no fueron ni muy completas, ni muy profundas. Vale decir que esta inicial cobertura periodística resultó parcial y episódica ${ }^{7}$. Así, por ejemplo, el 31 de marzo de 1918 se dio cuenta que había salido de Buenos Aires con rumbo a Córdoba el presidente de la Federación Universitaria Argentina, con el objeto de participar de una manifestación en favor de la declaración de huelga de los académicos locales, con el objeto de exigir varias reformas y el perfeccionamiento de los planes de estudio ${ }^{8}$. Casi dos semanas después se informa que el presidente Hipólito Yrigoyen estaba por designar un interventor federal para resolver el conflicto entre los estudiantes y las autoridades de la Universidad de Córdoba, y que la persona elegida

después se desempeñó como Rector de la Universidad Federal de Río de Janeiro.

6 Cfr. ABÁSOLO, Ezequiel. Aportes del comparatismo jurídico al estudio de la circulación de ideas y experiencias normativas en Europa y América durante la primera mitad del siglo XX. In: ABÁSOLO, Ezequiel. La cultura jurídica latinoamericana y la circulación de ideas durante la primera mitad del siglo XX. Buenos Aires: Instituto de Investigaciones de Historia del Derecho, 2014, pp. 16 a 20.

7 No hay que descartar el conocimiento que pudiese adquirirse a partir de la consulta directa de la prensa argentina, la cual, como digo más adelante, circulaba habitualmente entre los dirigentes brasileños.

8 Jornal do Brasil, 31 de marzo de 1918, p. 7. 
para esta tarea era el entonces Procurador General de la Nación, José Nicolás Matienzo9. Casi cinco meses más tarde, el 10 de septiembre del mismo año, la prensa carioca volvió a hacerse eco de la situación universitaria mediterránea, para indicar que continuaba "la agitación entre los estudiantes de Córdoba", y que éstos habían tomado la universidad ${ }^{10}$. No mucho más que esto fue lo que dijeron los medios brasileños.

Ahora bien, durante el fragor mismo de las expresiones estudiantiles cordobesas hubo un distinguido intelectual brasileño que tomó conocimiento directo de los acontecimientos aludidos. Se trató de Manuel de Oliveira Lima, quien el 16 de septiembre de 1918 se hizo presente en la capital de Córdoba, para ofrecer una conferencia sobre derecho internacional ${ }^{11}$. Oliveira Lima, a quien puede considerarse un émulo brasileño del intelectual argentino Ernesto Quesada $^{12}$, debido a sus equivalentes pasiones de bibliófilo, y al destino final del rico acervo libresco atesorado ${ }^{13}$, dejó sus impresiones sobre la Reforma en un interesante volumen, titulado En la Argentina, que fuera publicado por primera vez en São Paulo en 1920, y que recién conoció una edición en castellano en $1998^{14}$. En dicha obra -que relevantes figuras de su Brasil contemporáneo lle-

9 Jornal do Brasil, 11 y 12 de abril de 1918. Matienzo, nacido en 1860 y fallecido en 1936, había sido integrante de la Suprema Corte de Justicia de la provincia de Buenos Aires (19101913). Años después de ejercer su papel como interventor en Córdoba se desempeñó como ministro del interior del Presidente Alvear, y alcanzó el decanato de la facultad de Derecho de la Universidad Nacional de La Plata. Cfr. TAU ANZOATEGUI, Víctor [cord.]. Antología del pensamiento jurídico argentino (1901-1945), t. II. Buenos Aires: Instituto de Investigaciones de Historia del Derecho, 2008, p. 459.

10 Jornal do Brasil, 10 de septiembre de 1918.

11 Jornal do Brasil, 16 de septiembre de 1918. Véase también "Con el Dr.Oliveira Lima. Sus impresiones de Córdoba”, en La Voz del Interior (Córdoba), 15 de septiembre de 1918. Como parte de su viaje a la Argentina, Oliveira Lima ofreció una conferencia en Buenos Aires el 9 de agosto, y otra en La Plata el 24 del mismo mes. Sobre la figura de Oliveira Lima, pueden verse: PATEE, Richard. Manoel de Oliveira Lima, embajador intelectual del Brasil. Revista de la Universidad Católica del Perú (Lima), 1939. DINIZ FORSTER, María Theresa. Oliveira Lima e as relações exteriores do Brasil: o legado de um pioneiro e sua relevância para a diplomacia brasileira. Brasília: Fundação Alexandre de Gusmão, 2011. CORREA, Luiz Felipe de Seixas. Semblanza del autor. In: OLIVEIRA LIMA, Manuel de. En la Argentina. Buenos Aires: Centro de Estudios para la Nueva Mayoría, 1998.

12 Cabe aclarar que Oliveira Lima y Quesada mantuvieron trato personal durante la visita del primero a Buenos Aires, en 1918, contacto que se mantuvo luego por vía epistolar.

13 PAULA, Eurípedes Simões de. A Biblioteca Oliveira Lima da Universidade Católica da América. Revista de História (São Paulo), 55, vol. 110 (junio de 1977). LEAL, María Angela. «Longe da pátria, mas sem a esquecer»: print and non print collections at the Oliveira Lima Library. Remate de Males (São Paulo), vol. 24, núm. 2 (2004). JANSEN, Roberta. Astrofisica da NASA assume reitoria de universidade nos EUA e resgata acervo de diplomata brasileiro. O Estado de São Paulo, 21 de enero de 2018.

14 Se ha ocupado del viaje de Oliveira Lima por la Argentina y de este libro BAGGIO, Kátia Gerab. Impressões da vida política argentina em fins da década de 1910 por um diplomata e intelectual brasileiro: Manoel de Oliveira Lima. XII Jornadas Interescuelas/Departamentos de Historia. San Carlos de Bariloche: Departamento de Historia, Facultad de Humanidades y Centro Regional Universitario Bariloche. Universidad Nacional del Comahue, 2009. Sobre la 
garon a conocer, como fue el caso de Affonso Celso, de quien hablaremos más adelante ${ }^{15}-$, Oliveira Lima apuntó:

Tuve la oportunidad de asistir, por así decirlo, a la transformación universitaria argentina, esto es, a la radicalización de su enseñanza superior, llevada a cabo por iniciativa de los estudiantes en armonía con el espíritu general del momento histórico, dentro y fuera de la República. Aquellos a quienes no les agrada esta virtual preponderancia, no sólo moral sino también positiva, del cuerpo discente sobre el docente, comparan el nuevo estado de las cosas con el sistema de los soviets, equiparando a los estudiantes con los bolcheviques y olvidando que la culpa recae en gran parte sobre el profesorado. Éste se alejó bastante de sus deberes en los tiempos en que era el único poder, despreciando la simple tarea educativa, organizando camarillas pedagógicas que acababan negándose a la renovación intelectual y explotando la situación creada por las circunstancias y por la intención en beneficio de sus intereses, ofreciendo a los alumnos unas migajas de saber y utilizando la cátedra como pedestal para escalar posiciones políticas [...] De allí el dogmatismo de los planes de estudio, la pobreza de los programas, la insuficiencia de aplicación intelectual, todo bajo la inspiración y la tutela del Estado, según el criterio napoleónico o el concepto cesarista, del cual ha dicho el Dr.Ernesto Quesada, en una bella conferencia sobre el ideal universitario, que constituye un lecho de Procusto para la mentalidad de la Nación entera. En la actualidad se han visto alteradas profundamente las condiciones, justificando el entusiasmo de la juventud radical que en un telegrama enviado desde Córdoba al presidente de la República se denomina a sí misma «energía en germen y luz del porvenir» luchando para imponer definitivamente los ideales que el Sr.Yrigoyen «propagó y enseñó a amar como particular y a los que encarna magistralmente en las cumbres del poder» [...] El espíritu nuevo proclamado en Córdoba quería iniciar, bajo el amparo del Poder Ejecutivo, un camino que condujese a la liberación de toda influencia tradicional en un medio donde tal tradición se ejercía de un modo obstinado ${ }^{16}$.

A pesar de su importancia, el testimonio de Oliveira Lima no parece haber despertado mayor atención entre sus compatriotas. Y eso que, entonces, no sólo el clima brasileño era de especial atención hacia todo lo que tuviese origen en la Argentina, especialmente en materia jurídica, sino que, además, lo relativo a la Universidad, su papel y sus características preocupaban hondamente a los líderes del Brasil. En cuanto a la genérica atención brasileña hacia la Argentina y su derecho ${ }^{17}$, cabe referir, entre los muchos ejemplos posibles, que en 1910,

edición en castellano, véase la nota 11.

15 Affonso Celso le agradeció a Oliveira Lima el obsequio de su libro En la Argentina, mediante carta fechada en Rio de Janeiro el 18 de febrero de 1920. Cfr. The Catholic University of America, University Libraries, Oliveira Lima Library, correspondence [https://cuislandora.wrlc.org/ islandora /object /lima\%3A15344\#page/ 3/mode/1up], consultado el 12 de agosto de 2018.

16 Manuel de Oliveira Lima, ob. cit., pp. 126 a 128.

17 Además de mis propios aportes sobre los vínculos entre el derecho argentino y el brasileño de la primera mitad del siglo XX, pueden consultarse con provecho las valiosas contribuciones de Mariana de Moraes Silveira. Entre otros, puede citarse Bar Associations and the Circulation of Legal Knowledge: Argentina and Brazil, First Half of the Twentieth Century, In: TATE, Joshua C., LIMA LOPES, José Reinaldo de, BOTERO BERNAL [eds.]. Global Legal History. 
al discutirse la intervención federal al estado de Rio de Janeiro, los integrantes de la comisión de Constitución y Justicia de la Cámara de Diputados brasileña fundaron su opinión contraria a un proyecto del senador por Matto Grosso Antonio Azeredo recurriendo a una análoga experiencia argentina de 1899, y reproduciendo a lo largo de cinco páginas en castellano los argumentos vertidos por el diputado Vedia en el congreso argentino ${ }^{18}$. Hacia la misma época, y para referirse al carácter político no justiciable de algunas decisiones federales brasileñas, el diputado y bacharel paulista Cincinato Braga invocó cuatro decisiones de la Corte Suprema de Justicia de la Nación argentina. Entre ellas, el significativo pronunciamiento "Cullen con Llerena", de 7 de septiembre de $1893^{19}$. Es que para la década de 1910 no resultaba infrecuente que juristas, intelectuales y políticos brasileños se refiriesen a la Argentina y a lo argentino como "ejemplo" o como "modelo". Así, en cuanto a lo primero, entre una de la multitud de referencias posibles podemos traer a colación ahora una intervención efectuada en 1918 por el entonces joven diputado federal potiguar y graduado en derecho por la Universidad de Recife, José Augusto Bezerra de Medeiros ${ }^{20}$. En cuanto a lo segundo -Argentina como "modelo" institucional-, entiendo oportuno recordar los términos de un parecer legislativo de 1921, suscripto por los senadores Raul Soares, Eloy de Souza, Lopes Gonçalves y Antonio Moniz ${ }^{21}$. También puedo reproducir los elogiosos términos de un parecer de 10 de mayo de 1924 de la comisión de poderes del senado brasileño -integrada, entre otros, por Paulo de Frontin y Lauro Sodre- en el cual se recordó que "cuando la revolución mirífica

A Comparative Law Perspective. London: Routledge, 2018.

18 Véase la discusión sobre el proyecto núm. 7-1910, del senador A.Azeredo, Congresso Nacional, Annaes da Camara dos Deputados, sessões de 1 a 19 de setembro de 1910, vol. III, Rio de Janeiro, Imprensa Nacional, 1910, pp. 581 a 587.

19 Véase la sesión de la Cámara de Diputados brasileña de 20 de septiembre de 1910, en Annaes da Camara dos Deputados, sessões de 20 a 30 de setembro de 1910, vol. IV, Rio de Janeiro, Imprensa Nacional, 1910, p. 18. El pronunciamiento "Cullen con Llerena" se encuentra en Fallos de la Corte Suprema de Justicia de la Nación (en adelante, Fallos), t. 53, p. 420 y sigs. Cincinato Braga también citó la causa "José Roque Pérez en representación de la Provincia de Mendoza”, de 14 de noviembre de 1865 (Fallos, t. 2, p. 254); "Mariano Varela contra el comisario Avelino Anzó por haber mandado suspender la publicación de La Tribuna", de 21 de mayo de 1881 (Fallos, t. 23, p. 257); y "Eleodoro Lobos contra el interventor de la Provincia de Santa Fe, Daniel Donovan", de 28 de octubre de 1893 (Fallos, t. 54, p. 180). Los datos biográficos de Braga han sido tomados del verbete correspondiente del Dicionário Histórico-Biográfico Brasileiro (DHBB), del Centro de Pesquisa e Documentação de História Contemporánea do Brasil de la Fundación Getulio Vargas [www.fgv.br/cpdoc/acervo, consultado el 12 de agosto de 2018]. En adelante, citado como DHBB.

20 Véase la sesión de la Cámara de Diputados brasileña de 3 de septiembre de 1918, en Annaes da Camara dos Deputados, sessões de 2 a 19 de setembro de 1910, vol. VIII, Rio de Janeiro, Imprensa Nacional, 1919, pp. 66, 67 y 73. Sobre José Augusto, véase el verbete correspondiente -de autoría de Mauro Malin-, publicado en Dicionário Histórico-Biográfico Brasileiro (DHBB), consultado el 12 de agosto de 2018.

21 Cfr. Annaes do Senado Federal, sessões de 1 a 30 de junho de 1921, volume II, Rio de Janeiro, Imprensa Nacional, 1922, pp. 162 y 166. 
de 15 de noviembre de 1889 transformó nuestro país, poniendo en el lugar de la realeza decrépita y vencida la república victoriosa y fuerte, fuimos a pedirle a la América del Norte, como un modelo completo y bien acabado, nuestras instituciones, recogiendo también las lecciones que nos podían proporcionar otros países americanos regidos por normas idénticas a las de la grande patria de Washington, destacándose entre todos ellos la República Argentina”"22. Sin lugar a dudas, la deferencia brasileña con lo argentino reflejaba una fuerte admiración por los vecinos del sur, la misma que, por ejemplo, sin despertar ningún tipo de manifestación contraria por parte de sus colegas, condujo al diputado paulista en el congreso federal Antonio Carlos de Salles Junior -antiguo integrante del legislativo estadual, y futuro secretario de justicia de su São Paulo natal, entre 1927 y 1930- a afirmar que el medio geográfico tornaba al hombre argentino superior al brasileño ${ }^{23}$. Tan extendida y aceptada era, entonces, la noción de la pretendida superioridad argentina sobre lo local ${ }^{24}$, que al decir de un destacado intelectual no se conocía en Rio de Janeiro ni en los estados del interior "una sola página periodística argentinófoba, o que pretenda deprimir, menospreciar, o esconder las altas cualidades y avanzados progresos de la tierra de Roca y Sáenz Peña”25.

\section{LAS UNIVERSIDADES ARGENTINAS, EN LA MIRA DE LOS JURISTAS BRASILEÑOS}

Un aspecto de la Argentina que suscitaba especial atención por parte de los pedagogos y juristas brasileños de comienzos del siglo XX era el referido al estado de la educación superior. Así, por ejemplo, podemos recordar los términos de un elogioso artículo del escritor, educador y vicepresidente de la Sociedad de Geografía de Rio de Janeiro, Lindolpho Xavier, titulado "La República Argentina" ${ }^{26}$. En él, al referirse a la ciudad de La Plata, dice que la misma estaba "ligada a Buenos Aires por un ferrocarril de 80 kilómetros", y que contaba con "una gran universidad”. Por su parte, ocho años más tarde Affonso Celso destacó que desde 1923 se celebraban en la Argentina congresos universitarios anuales, con representantes de las corporaciones universitarias. El destacado intelectual

22 Cfr. sesión de 15 de mayo de 1924. En Annaes do Senado Federal, sessões de 27 de abril a 31 de maio de 1924, volume I, Rio de Janeiro, Imprensa Nacional, 1926, p. 489.

23 Véase la sesión de 30 de julio de 1918 en Annaes da Camara dos Deputados, sesiones de 17 a 31 de julho de 1918, vol. V, Rio de Janeiro, Imprensa Nacional, 1919, p. 769. Se pueden recabar algunos datos biográficos de Antonio Carlos de Salles Junior en CHAVES, Marcelo Antonio. A trajetória do Departamento Estadual do Trabalho de São Paulo e a mediação das relações de trabalho (1911-1937). Campinas, SP: 2009. Tesis de doctorado, Universidade Estadual de Campinas, Instituto de Filosofia e Ciências Humanas, p. 44.

24 Véase lo que dice el senador Carlos Cavalcanti en Annaes do Senado Federal, sessões de 16 a 30 de novembro de 1923, volume VIII, Rio de Janeiro, Imprensa Nacional, 1927, p. 824.

25 CELSO, Affonso. Intercambio espiritual. La Universidad de La Plata. Simpático mensaje. Jornal do Brasil, 22 de junio de 1922, p. 6.

26 Jornal do Brasil, 12 de agosto de 1919, p. 8, 
mineiro afincado en Rio glosaba con deleite el libro La Universidad Nacional de La Plata en el año 1926, mandado editar por el presidente de la institución, Benito Nazar Anchorena, el cual, al decir de Celso, había tenido la gentileza de obsequiarle un ejemplar, y comparaba, no sin desazón, la situación universitaria de La Plata con el "simple modus vivendi entre los tres institutos" que componían la Universidad de Rio de Janeiro, "programa trazado por el Consejo de Enseñanza Superior en $1925^{27}$. Ahora bien, Affonso Celso no fue el único jurista brasileño para quien la Universidad de La Plata se erigió en alabado modelo de institución de educación superior. Sabemos, por ejemplo, que en 1922, preocupado por la situación de los estudios universitarios del país y tras una sesuda intervención parlamentaria, el senador Irineu Machado manifestó su admiración por el modelo de universidad impulsado en la ciudad de La Plata. "Bajo mi punto de vista", proclamó "el verdadero tipo de universidad es el que fue concebido por la mente prodigiosa de Joaquín González, el gran senador argentino, que pasa por ser la mayor cabeza entre los juristas de aquel país". Y luego compartió con sus colegas de la cámara: "Él me tendió su mano santa para llevarme por todas las salas y departamentos de la gran Universidad de La Plata, la cual, en mi opinión expresa la más vasta concepción, la más completa de todas las concepciones de universidad. Yo la recorrí y la examiné. Pasé algunos días. Allí, en aquella intimidad, en aquel reinado de la inteligencia, del saber y de la simplicidad, admiré lo que es el esfuerzo de una inteligencia y el valor de una concepción, servida por una fe honesta y un alma sin imperfección" ${ }^{28}$. Narrado lo anterior se entiende el por qué del homenaje ofrecido en la cámara alta del Brasil en 1923, cuando habiéndose tomado noticia del fallecimiento del intelectual riojano, el senador Augusto Cesar Lopes Gonçalves, graduado en derecho por Recife y por aquel entonces representante por Amazonas" ${ }^{29}$, hizo uso de la palabra para decir "hace pocos días falleció en Buenos Aires el eminente político y publicista, senador Joaquín González, quien por más de una vez ocupó el elevado cargo de ministro en aquella República vecina y amiga. El difunto, en diversas monografías, especialmente sobre derecho constitucional, reveló siempre grandes conocimientos, sagacidad de vista, sabiduría profunda, perfecta ciencia de las tradiciones y de la historia de los diversos países que cultivan el régimen liberal, principalmente en su gran obra, Manual de Derecho Constitucional" ${ }^{30}$.

27 CELSO, Affonso. Universidades Argentinas. Jornal do Brasil, 20 de diciembre de 1927, p. 5.

28 Cfr. sesión de 14 de octubre de 1922. En Annaes do Senado Federal, sessões de 2 a 30 de outubro de 1922, volume VIII, Rio de Janeiro, Imprensa Nacional, 1925, pp. 214 a 216.

29 Verbete "Augusto Cesar Lopes Gonçalves”, a cargo de Maria Eugenia Bertarelli. En DHBB, cit., consultado el 12 de agosto de 2018.

30 Sesión de 30 de diciembre de 1923 en Annaes do Senado Federal, sessões de 29 a 30 de dezembro de 1923, vol. XV, Rio de Janeiro, Imprensa Nacional, 1930, p. 531. 


\section{RASTREO DE LAS VÍAS DE CIRCULACIÓN DE LA EXPERIENCIA CORDOBESA EN EL BRASIL}

Más allá del genérico interés local en las experiencias universitarias argentinas, podría aventurarse que una de las posibles vías de específico conocimiento brasileño sobre la experiencia reformista cordobesa se produjo como consecuencia de contactos directos entablados entre docentes e intelectuales del país con pares oriundos de Córdoba. Es cierto que éstos existieron. Sin embargo, resultaron tardíos respecto del inicial conocimiento en el Brasil de la Reforma. A ciencia cierta, recién hubo importante presencia de cordobeses en el Brasil a partir de 1927. Así, en agosto de ese año, el profesor cordobés Víctor Romero del Prado, dedicado al cultivo del derecho internacional privado, integró la delegación de abogados argentinos que visitaron el Brasil con motivo de la celebración del centenario de los cursos jurídicos superiores ${ }^{31}$. Más de un lustro después fue el turno de Enrique Martínez Paz, entonces presidente del Superior Tribunal de Justicia de Córdoba y también docente de la Universidad Nacional homónima, quien concurrió a la capital carioca ${ }^{32}$.

Es verdad que Martínez Paz, de asiduo contacto con Clovis Bevilaqua, ya era entonces bastante identificado en el Brasil. Ahora, bien, su fama se vinculaba, principalmente, a sus elogiosos juicios sobre el código brasileño de 1916. De este modo, por ejemplo, puede recordarse que durante 1923, entre los argumentos vertidos por el diputado federal Solidonio Leite contra el proyecto de ley presentado por de su par bahiano João Mangabeira sobre el Banco Hipotecario, se sostuvo que:

Los estatutos del Banco fueron hechos de acuerdo con la carta orgánica del Banco Hipotecario Nacional de Argentina, creado por ley 1804, y modificada por las leyes 8172,9155 y 10676 . No se atendió, por ello, a las diferencias profundas que hay entre el código civil argentino, hecho hace muchos años en base al Esboço de nuestro Teixeira de Freitas, y nuestro código de 1916, incomparablemente mucho más adelantado, según reconocen los competentes, incluso las mayores autoridades de la propia Argentina, bastando citar Martínez Paz de la Universidad de Córdoba, y Alfredo Colmo de la Universidad de Buenos Aires, quien al decir que la sanción del código civil brasileño fue el acontecimiento jurídico del siglo, en la parte latina de nuestro continente, agregó: 'y cualquiera de nuestros países, que necesite revisar su ley civil deberá recorrer en muchos puntos al código brasileño para recibir buenas inspiraciones de metodología, de técnica, de ciencia, de tendencias liberales y modernas ${ }^{33}$.

El recordado Martínez Paz volvió al Brasil en julio de 1938, oportunidad en la que fue recibido por el Instituto de los Abogados. Otros juristas cordobeses

31 La llegada de la delegación de abogados argentinos. En conmemoración del Centenario de los cursos jurídicos en Río. Jornal do Brasil, 9 de agosto de 1927, p. 7.

32 Jornal do Brasil, 2 de junio de 1933, p. 18.

33 Jornal do Brasil, 5 de septiembre de 1923, p. 13. 
también estuvieron en Rio durante el mismo mes, como el ya recordado Romero del Prado ${ }^{34}$. Para ese entonces, tan extendido estaba el conocimiento brasileño sobre Córdoba, que hasta llegó a hablarse de erigir en São Francisco, estado de Santa Catarina, un monumento en homenaje a Hernando de Trejo y Sanabria, fundador de la Universidad de Córdoba ${ }^{35}$.

Para finales de la década de 1920 y comienzos de la siguiente, el panorama de conocimiento brasileño sobre Córdoba había mudado, indudablemente. Piénsese que durante los años previos, una profunda ignorancia local había llevado a decir, tras confundir la antigua toponimia colonial de "Córdoba del Tucumán", que la Universidad de Córdoba se encontraba "en la actual provincia de Tucumán”, lo cual, para que se entienda lo grueso del error, resultaría equivalente a afirmar algo así como que la sede de Largo de Sao Francisco estaba en Minas Gerais... ${ }^{36}$. Ahora bien, además de juristas también recorrieron el Brasil universitarios cordobeses de otras disciplinas, como Benito Soria, profesor de la facultad de medicina de la Universidad mediterránea ${ }^{37}$. De este modo, el 3 de abril de 1927 llegó a la capital paulista "como portador de mensajes de congratulaciones del Rectorado de la Universidad de Córdoba”, con motivo de la celebración del 14 aniversario de la instalación de la Facultad de Medicina. Unos meses antes también había estado en Rio de Janeiro otro destacado cordobés, en este caso, jurista y muy identificado con el movimiento reformista. Se trató del profesor de Derecho Industrial Dardo Rietti, quien fuera recibido por el director de la Facultad carioca, Manoel Cicero, y otros profesores, entre ellos, el catedrático de derecho internacional privado, Rodrigo Octavio ${ }^{38}$.

Ahora bien, entiendo que no fue mediante el contacto con viajeros cordobeses que los brasileños de la época se acercaron a la Reforma Universitaria. Entonces, ¿Se debió esto al contacto con jóvenes estudiantes? Que los vínculos estudiantiles existieron, y que éstos contribuyeron a la difusión local de la reforma universitaria argentina, no caben dudas. Sin embargo, también este vehículo de información resultó relativamente tardío, como que las noticias sólidas con las que cuento a la fecha sobre contactos reformistas entre estudiantes argentinos -no necesariamente cordobeses- y brasileños no se remontan sino a 1926.

34 Jornal do Brasil, 21 de julio de 1938, p. 11.

35 BARBOSA DE OLIVEIRA, C.A. Universidad de Córdoba. Jornal do Brasil, 10 de agosto de 1938, p.6.

36 CELSO, Affonso. La Universidad brasileña. Jornal do Brasil, 8 de enero de 1919, p. 5.

37 Jornal do Brasil, 3 de abril de 1927, p. 4.

38 Jornal do Commercio, 13 de enero de 1927, p. 4. Sobre la figura de Dardo Rietti puede consultarse PORTELLI, María Belén. Itinerario de un experto. Dardo Rietti, el derecho del trabajo y el proceso de construcción de las políticas laborales, Córdoba, 1920-1931. Cuadernos del CIESAL, ${ }^{\circ} 11$ (enero-diciembre de 2012). ASPELL, Marcela y YANZI FERREIRA, Ramón Pedro. La enseñanza del derecho del trabajo en la Facultad de Derecho y Ciencias Sociales de la Universidad Nacional de Córdoba. Cuadernos de Historia (Córdoba), Academia Nacional de Derecho y Ciencias Sociales de Córdoba, nº 13 (2003). 
Curiosamente, quien cobró bastante importancia en este proceso fue un intelectual boliviano. Se trató de Roberto Hinojosa, nombrado en 1926 secretario de legación de la embajada de su país en el Brasil ${ }^{13}$. En el curso de una entrevista publicada en Rio de Janeiro en agosto del año mencionado, Hinojosa se presenta como el enviado de los universitarios bolivianos, argentinos y uruguayos para entablar vínculos con sus pares brasileños. En la oportunidad, y entre otros conceptos, Hinojosa afirmó, también, que además de preocupaciones inherentes a la situación internacional, el movimiento universitario latinoamericano de la época respondía a sensibles inquietudes estudiantiles, análogas a las planteadas por "la reforma universitaria, según se estableció en Córdoba, en el año 1918", las cuales merecieron ser difundidas por los profesores argentinos -varios de ellos, de filiación socialista- Alfredo L.Palacios, Florentino Sanguinetti, Carlos Sánchez Viamonte, y Julio V.González. Conforme los dichos del intelectual boliviano, "los universitarios quieren gobernarse, exigen que se respeten sus derechos ... Esto es, quieren autonomía universitaria, cambios en la enseñanza" ${ }^{40}$. Cuatro meses más tarde Hinojosa pronunció una conferencia en la Academia de Bellas Artes de Rio, la misma que, aunque con reservas por su extremismo, suscitó que el Jornal do Brasil la elogiara en tanto que expresión del "esfuerzo que realizan vigorosamente las nuevas fuerzas espirituales, en nuestro continente, en una lucha de principios nobles y enérgicos, por la defensa de los más adelantados principios de la ciencia política contemporánea”. En su exposición, el disertante aludió al fracaso de la cultura occidental del viejo mundo, y resaltó que "la Universidad de la docta Córdoba" había dado "el año 1918, el primer toque de clarín contra las ideologías caducas y contra los profesores que no comprendían las necesidades espirituales de la juventud moderna" ${ }^{41}$. Medio año después se produciría la visita de universitarios uruguayos a la capital, transmitiendo al público brasileño posiciones análogas a las referidas ${ }^{42}$.

Cabe aclarar que con el transcurso de los años, la militancia estudiantil lejos estuvo de aplacarse, cobrando, en cambio, creciente dimensión política en el Brasil. Así, por ejemplo, en 1929 el presidente de São Paulo, Julio Prestes, se reunió con jóvenes universitarios cariocas, con el objeto de compartir con ellos sus ideas "respecto de la ja fallida reforma universitaria, por la cual vienen trabajando tanto todos los elementos asociativos que representan a la juventud

39 La novelesca trayectoria de este personaje es retratada por SCHELCHKOY, Andrey. Roberto Hinojosa: ¿revolucionario nacionalista o Goebbels criollo?. Revista Izquierdas (Universidad de Santiago de Chile), vol. 1, $\mathrm{n}^{\circ} 2$ (diciembre de 2008).

40 Un homenaje de los universitarios de Bolivia, de Argentina y del Uruguay a la juventud estudiosa brasileña. Habla al Jornal do Brasil el Doctor Roberto Hinojosa. Jornal do Brasil, 25 de agosto de 1926, p. 7.

41 La juventud sudamericana. Jornal do Brasil, 31 de diciembre de 1926, p. 5.

42 La visita de los universitarios uruguayos. Lo que dijo al Jornal do Brasil el vicepresidente de la delegación, bacharel Augusto César Brado. Jornal do Brasil, 19 de julio de 1927, p. 6. 
estudiosa" ${ }^{43}$. De análoga manera, producida la revolución liderada por Getúlio Vargas la cuestión universitaria volvió a tomar temperatura. Así, la crónica periodística informa que el sábado 22 de noviembre de 1930 los estudiantes agrupados en el Directorio Académico de la Facultad de Derecho se reunieron para deliberar ante la posibilidad de que el nuevo gobierno impulsase la reforma universitaria ${ }^{44}$. Tres meses más tarde, el profesor Bruno Lobo dictaría en São Paulo una conferencia sobre el tema, invitado por el Centro Once de Agosto, de la Facultad de Derecho ${ }^{45}$

Ahora bien, si no fueron los profesores cordobeses, ni los estudiantes argentinos los que iniciaron la difusión en el Brasil de la Reforma Universitaria ¿cuál pudo ser la vía que sí lo hizo posible? ¿La circulación de libros y de periódicos? Téngase presente que en algunas oportunidades las novedades argentinas llegaban a conocimiento brasileño por este medio con sorprendente velocidad. Un ejemplo significativo lo proporciona el caso de la ley argentina 11157, de congelamiento de alquileres -norma sobre cuyo ambiente intelectual y alcances ofrece información la distinguida colega Claudia Somovilla ${ }^{46}$. En efecto, sancionada el 15 de septiembre de 1921 y promulgada cuatro días más tarde, fue objeto de discusión y análisis parlamentario por parte del senador carioca graduado de bacharel en Recife, Irineu Machado ${ }^{47}$, apenas transcurrido un día desde su publicación oficial "en la culta y adelantada ciudad de Buenos Aires" ${ }^{48}$. Sucede que además de las publicaciones oficiales y del trabajo de difusión desplegado por los integrantes del cuerpo diplomático argentino acreditado en el Brasil, jugaban un papel destacado en la circulación de las novedades normativas y académicas la correspondencia personal y los periódicos. En este último sentido, no está de más recordar el rol significativo que desempeñó el diario porteño $L a$ Nación, anticipándose al arribo de las publicaciones oficiales argentinas a Rio de Janeiro y a São Paulo ${ }^{49}$.

43 Jornal do Brasil, 10 de agosto de 1929, p. 6.

44 La cuestión de la reforma universitaria. La contribución de la Facultad de Derecho. Jornal do Brasil, 25 de noviembre de 1930, p. 10.

45 Jornal do Brasil, 7 de febrero de 1931, p. 12.

46 La crisis habitacional y el acceso a la vivienda (1916-1930) - Intervencionismo estatal en los contratos de alquileres. Aequitas, año 8, vol. 8 (2014), p.194 y sigs.

47 Cfr. Surama Conde Sá Pinto, verbete “Irineu Machado", en DHBB, consultado el 12 de agosto de 2018.

48 Annaes do Senado Federal, sessões de 1 a 30 de setembro de 1921, volume V, Rio de Janeiro, Imprensa Nacional, 1922, p. 526.

49 Pueden verse invocaciones a La Nación como fuente de conocimiento del derecho y la realidad argentina en las palabras del senador Irineu Machado, en Annaes do Senado Federal, sessões de 1 a 30 de setembro de 1921, vol. V, Rio de Janeiro, Imprensa Nacional, 1922, p. 526. También en los fundamentos de la enmienda 52 al proyecto de presupuesto federal, presentada por el senador C.Cavalcanti, Annaes do Senado Federal, sessões de 15 a 22 de dezembro de 1921, vol. IX, Rio de Janeiro, Imprensa Nacional, 1922, p.361, y en la intervención del senador Paulo de Frontin, en Annaes do Senado Federal, sessões de 13, 14, 15, 17 e 18 de dezembro de 1923, vol. 


\section{UN PROBLEMA LOCAL, EN LA RAÍZ DE LA DIFUSIÓN EN EL BRASIL DE LA REFORMA UNIVERSITARIA ARGENTINA}

A despecho de la posterior relevancia de las vías de comunicación de la Reforma abordadas hasta el momento, entiendo que el gran responsable de su difusión en el Brasil fue un intelectual brasileño, significativamente preocupado por la situación de la enseñanza jurídica superior. Me refiero al conde de Affonso Celso, responsable de una influyente columna de opinión en el Jornal do Brasil ${ }^{50}$, y docente ligado al establecimiento de la Universidad de Rio de Janeiro en $1920^{51}$, institución de la cual llegó a desempeñarse como Director de su Facultad de Derecho por espacio de seis años, y brevemente como su Rector, en 1925, cargos que abandono simultáneamente tras considerar vulneradas "esenciales prerrogativas de la Universidad" 52 . Desde 1891 funcionaban en Rio dos facultades jurídicas, la de derecho, y la de ciencias jurídicas y sociales, ambas libres y equiparadas a las oficiales, siendo fusionadas en virtud de decreto 14163 de 12 de mayo de $1920^{53}$. Hondamente preocupado por la situación universitaria, pues, Affonso Celso tomó verdadero contacto con la Reforma Universitaria argentina en 1922, momento desde el cual se preocupó por difundir los alcances del movimiento entre sus compatriotas. Su fuente de información y entusiasmo parece haber sido el profesor Alfredo Palacios, quien a su prestigio intelectual como impulsor del derecho del trabajo en la Argentina, su militancia socialista, y su destacada capacidad oratoria, aunaba un desempeño institucional que para los brasileños del momento resultaba extraordinariamente importante. Me refiero al ejercicio del decanato de la Facultad de Ciencias Jurídicas de la Universidad Nacional de la Plata, institución que, como ya se ha dicho, entonces resultaba modélica entre los integrantes de los más elevados círculos académicos y políticos del Brasil. Profundo simpatizante de la Reforma Universitaria, como resultado de la visita que efectuó al país con motivo de la celebración del centenario de la independencia -oportunidad en la que recorrió la Universidad de São Paulo, de la cual se formó una impresión poco satisfactoria ${ }^{54}$-, Palacios entabló relaciones con varios destacados juristas brasileños. Entre ellos con su par de la Facultad de Derecho de Rio de Janeiro, que no era otro que Affonso Celso. Con motivo de este contacto inicial, Palacios criticó el hecho de que la universidad argentina hubiese permanecido aislada de las universidades extranjeras durante mucho tiempo y de espaldas a la

\footnotetext{
X, Rio de Janeiro, Imprensa Nacional, 1929, p. 391.
}

50 Cfr. SENNA, Homero, Literatura: A prosa. In: SEVERO DA COSTA, Luiz Antônio y otros. Brasil 1900-1910. Rio de Janeiro: Biblioteca Nacional, 1980, vol. 3, p. 101.

51 Jornal do Brasil, 5 de noviembre de 1920, p. 7.

52 CELSO, Affonso. En pro de la Universidad. Jornal do Brasil, 9 de noviembre de 1926, p. 5.

53 CELSO, Affonso. La Facultad de Derecho de la Universidad. Es oficial o equiparada? Reforma imprescindible. Jornal do Brasil, 14 de julio de 1922, p. 6.

54 CELSO, Affonso. La reforma universitaria argentina. Jornal do Brasil, 6 de marzo de 1926, p. 5. 
realidad concreta, problemática que resultaba particularmente significativa para Celso. Conforme Palacios, la situación había sufrido un cambio profundo con la Reforma, movimiento que consideraba "genuina manifestación de espíritus jóvenes", y del cual destacaba la participación de alumnos y de graduados en la designación de autoridades, la asistencia y docencia libres, y la dedicación de la universidad a la investigación ${ }^{55}$.

La favorable impresión causada en el Brasil por Palacios se incrementó para finales de 1924, cuando el jurista argentino emitió un manifiesto dirigido a "La juventud universitaria de América Latina”. Allí apelaba a los estudiantes, invitándolos a "recorrer el camino de la nueva era del continente nuevo" ${ }^{56}$. Conforme Palacios "nuestra América, hasta hoy, ha vivido de Europa, teniéndola por guía. Su cultura la ha nutrido y orientado. Pero la última guerra ha hecho evidente lo que ya se adivinaba: que en el corazón de esa cultura iban los gérmenes de su propia disolución. Su ciencia estaba al servicio de las minorías dominantes y alimentaba la lucha del hombre contra el hombre. Ciencia sin espíritu, sin alma, ciega y fatal como las leyes naturales, instrumento inconsciente de la fuerza, que no escucha los lamentos del débil y el humilde; que da más a los que tienen, y remacha las cadenas del menesteroso; que desata en la especie los instintos primarios contra los más altos fines de la humanidad". El profesor argentino instaba a volver "la mirada a nosotros mismos. Reconozcamos que no nos sirven los caminos de Europa ni las viejas culturas. Estamos ante nuevas realidades". Preconizaba "una incruenta revolución: la revolución del pensamiento, la reforma educativa para transformar al hombre. Vosotros, universitarios de la nueva generación, habéis iniciado esa obra y debéis continuarla". Para hacer efectivos sus anhelos, Palacios instaba "transformar el alma de las universidades", convirtiéndolas en "laboratorios de humanidad". En este sentido, la renovación de la enseñanza universitaria exigía estudiar los acuciantes problemas sociales de la época ${ }^{57}$. No debe sorprendernos que la vigorosa convocatoria de Palacios resultase favorablemente recibida en recibida en la Cámara de Diputados del Brasil por obra del bacharel carioca graduado en São Paulo Nicanor do Nascimento ${ }^{58}$.

Ahora bien, tras la simpatía inicial con la cual Affonso Celso recibió las auspiciosas impresiones de Alfredo Palacios sobre la Reforma Universitaria, su entusiasmo se aplacó al conocer los juicios en la materia vertidos por el destacado juez y civilista argentino Alfredo Colmo. En 1925 éste dio a conocer su libro

55 CELSO, Affonso. Intercambio espiritual. La Universidad de La Plata. Simpático mensaje. Jornal do Brasil, 22 de junio de 1922, p. 6.

56 «La juventud universitaria de América Latina» (un brillante mensaje del Director de la Facultad de Ciencias Jurídicas y Sociales de la Universidad de La Plata). Jornal do Brasil,4 de diciembre de 1924, p.6.

57 El mensaje de Palacios se reprodujo en su libro La Universidad Nueva, Buenos Aires, M.Gleizer editor, 1925 , pp. 230 a 233.

58 Cfr. La Universidad Nueva, cit., p. 235. 
Política cultural en los países latinoamericanos, en el cual reprodujo el contenido de una ponencia expuesta en Lima, Perú, con motivo de la celebración del Tercer Congreso Científico Panamericano (22 de diciembre de 1924- 5 de enero de 1925). Si bien las actas de dicho encuentro no se publicaron sino en 1938, de inmediato circularon reseñas significativas en cuanto al contenido de sus deliberaciones, como una de Enrique Martínez Paz. Conforme Celso, la posición de Colmo merecía "atenta lectura", sobre todo teniendo en cuenta las deficiencias de la enseñanza superior brasileña, cuyas universidades distaban de ser "lo que deben ser, o sea, talleres de investigación científica y de formación de hombres" ${ }^{59}$. Acusando recibo de los conceptos de Colmo, a comienzos de febrero de 1926 Affonso Celso recordó a sus lectores del Jornal do Brasil que en 1918 “cambió fundamentalmente el régimen administrativo de las facultades que componen la Universidad de Buenos Aires. El Consejo Directivo de quince miembros, incluido el decano presidente, que hasta entonces gobernaba aquel instituto, era elegido por una asamblea de profesores -todos catedráticos o substitutos en ejercicios". A partir de la transformación, había comenzado la participación de los alumnos en la dirección académica, intentando "convertir en realidad la república universitaria”. Empero, los hechos no habían respondido a las pretensiones originales. Huelgas, hostilidad de alumnos a profesores, conflictos universitarios, irregularidad de cursos, cambio de autoridades, expresiones todas de un movimiento que aparecía como prematuro y violento. De allí que Colmo propusiera en Lima: "La intervención de los estudiantes en la designación de las autoridades universitarias, y su representación ante ellas, es un ideal a perseguirse. En este sentido, la reforma debe ser gradual”. ¿Qué interpretaba Celso de todo lo dicho? Algo que para los estudiantes argentinos no resultaba esencial del movimiento reformista, sino para nuestro intelectual brasileño. O sea, la instauración de "centros de investigación personal, disciplinados a voluntad de los estudiantes, permitiendo que cada joven sea escultor de su propio cerebro y hasta los menos dotados sean susceptibles, a la manera de las tierras pobres bien cultivadas y abonadas, de rendir abundantes frutos" ${ }^{60}$. No conforme con lo dicho en febrero, en marzo siguiente Affonso Celso volvió sobre el asunto, para sentenciar categóricamente: "Según el ilustre profesor y publicista argentino Doctor Alfredo Colmo, cuya opinión registramos y comentamos en este periódico, la reforma universitaria realizada en su país, en 1918, y modificada en 1923, no produjo los benéficos efectos esperados, sino que, por el contrario, produjo serios inconvenientes que reclaman nuevas modificaciones. Produjo, sobre todo, resultados negativos" ${ }^{61}$.

59 CELSO, Affonso. Política cultural. Nobles objetivos. Orgullo nacional. Jornal do Brasil, 26 de enero de 1926, p. 5.

60 Affonso Celso, "Cuestiones universitarias. Intervención de los alumnos. La experiencia argentina", Jornal do Brasil, 2 de febrero de 1926, p. 5.

61 Affonso Celso, "La reforma universitaria argentina", Jornal do Brasil, 6 de marzo de 1926, p. 5. 


\section{CONSIDERACIONES FINALES}

Expresión de lo que cabe denominar como "flujo horizontal" -o sea, relación entre comunidades ajenas a vínculos inconmovibles bajo el pretendido formato de "centros" y de "periferias"- de ideas y de propuestas pedagógicas relevantes para la formación de los juristas, la primera repercusión de la Reforma Universitaria argentina en el Brasil comprende, con rasgos propios, tres asuntos de recurrente aparición en el estudio de todo fenómeno de circulación de componentes de cultura jurídica. Me refiero, primero, al problema de las vías o modos de acceso al conocimiento de los fragmentos que se trate de cultura jurídica. En nuestro caso, se identifica la simultánea relevancia de las visitas académicas, los contactos personales, el acceso a la literatura y la función difusora de la prensa periódica. En segundo lugar, se trata del tema de las causas o motivos de la circulación de estos fragmentos, lo cual tiene mucho que ver con los sentidos que la apropiación de lo foráneo pueden terminar asumiendo en un contexto diferente al de su origen. En lo que hace a la Reforma Universitaria en concreto, queda claro que la preocupación brasileña de la hora no consistía en el mayor o menor acceso del estudiantado al gobierno de las instituciones educativas, sino a la pretensión de dotarlas de mayor calidad en el diseño de sus esfuerzos de investigación, razón que llevó a una lectura sesgada del movimiento argentino. $\mathrm{Y}$ en tercer lugar aparece el asunto de las responsabilidades y de las genealogías de las transferencias, cuestión que en este caso encuentra en la figura de Affonso Celso al mediador inicial por excelencia de las experiencias universitarias argentinas en el Brasil.

\section{BIBLIOGRAFÍA}

ABÁSOLO, Ezequiel. Aportes del comparatismo jurídico al estudio de la circulación de ideas y experiencias normativas en Europa y América durante la primera mitad del siglo XX. In: . La cultura jurídica latinoamericana y la circulación de ideas durante la primera mitad del siglo XX. Buenos Aires: Instituto de Investigaciones de Historia del Derecho, 2014.

ASPELL, Marcela y YANZI FERREIRA, Ramón Pedro. La enseñanza del derecho del trabajo en la Facultad de Derecho y Ciencias Sociales de la Universidad Nacional de Córdoba. Cuadernos de Historia (Córdoba), Academia Nacional de Derecho y Ciencias Sociales de Córdoba, nº 13 (2003).

BAGGIO, Kátia Gerab. Impressões da vida política argentina em fins da década de 1910 por um diplomata e intelectual brasileiro: Manoel de Oliveira Lima. XII Jornadas Interescuelas/Departamentos de Historia. San Carlos de Bariloche: Departamento de Historia, Facultad de Humanidades y Centro Regional Universitario Bariloche. Universidad Nacional del Comahue, 2009. 
BIAGINI, Hugo. E. La reforma universitaria. Antecedentes y consecuentes. Buenos Aires: Leviatán, 2000,

BUCHBINDER, Pablo. Pensar la reforma universitaria cien años después. Revista Iberoamericana de Educación Superior (México), UNAM-IISUE/Universia, vol. ix, núm. 25.

CORREA, Luiz Felipe de Seixas. Semblanza del autor. In: OLIVEIRA LIMA, Manuel de. En la Argentina. Buenos Aires: Centro de Estudios para la Nueva Mayoría, 1998.

CHAVES, Marcelo Antonio. A trajetória do Departamento Estadual do Trabalho de São Paulo e a mediação das relações de trabalho (1911-1937). Campinas, SP: 2009. Tesis de doctorado, Universidade Estadual de Campinas, Instituto de Filosofia e Ciências Humanas.

DEL MAZO, Gabriel volumen II, La Plata: Centro de Estudiantes de Ingeniería, 1941.

DINIZ FORSTER, María Theresa. Oliveira Lima e as relações exteriores do Brasil: o legado de um pioneiro e sua relevância para a diplomacia brasileira. Brasília: Fundação Alexandre de Gusmão, 2011.

JANSEN, Roberta. Astrofísica da NASA assume reitoria de universidade nos EUA e resgata acervo de diplomata brasileiro. O Estado de São Paulo, 21 de enero de 2018.

LEAL, María Angela. «Longe da pátria, mas sem a esquecer»: print and non print collections at the Oliveira Lima Library. Remate de Males (São Paulo), vol. 24, núm. 2 (2004).

OLIVEIRA LIMA, Manuel de. En la Argentina. Buenos Aires: Centro de Estudios para la Nueva Mayoría, 1998.

PALACIOS, Alfredo. La Universidad Nueva. Buenos Aires: M.Gleizer editor, 1925,

PASTRANA RODRIGUEZ, Eduardo. La reforma universitaria, el movimiento de Córdoba y sus repercusiones en Colombia. Educere. Foro Universitario (Cali, Colombia), año 12, núm. 41 (abril-junio de 2008).

PATEE, Richard. Manoel de Oliveira Lima, embajador intelectual del Brasil. Revista de la Universidad Católica del Perú (Lima), 1939.

PAULA, Eurípedes Simões de. A Biblioteca Oliveira Lima da Universidade Católica da América. Revista de História (São Paulo), 55, vol. 110 (junio de 1977).

PORTANTIERO, Juan Carlos. Estudiantes y política en América Latina. El proceso de la reforma Universitaria (1918-1938). México: Siglo XXI, 1979. 
PORTELLI, María Belén. Itinerario de un experto. Dardo Rietti, el derecho del trabajo y el proceso de construcción de las políticas laborales, Córdoba, 19201931. Cuadernos del CIESAL, ${ }^{\circ} 11$ (enero-diciembre de 2012).

SCHELCHKOY, Andrey. Roberto Hinojosa: ¿̇evolucionario nacionalista o Goebbels criollo?. Revista Izquierdas (Universidad de Santiago de Chile), vol. 1, $\mathrm{n}^{\circ} 2$ (diciembre de 2008).

SILVEIRA, Mariana de Moraes. Bar Associations and the Circulation of Legal Knowledge: Argentina and Brazil, First Half of the Twentieth Century. In: TATE, Joshua C., LIMA LOPES, José Reinaldo de, BOTERO BERNAL [eds.]. Global Legal History. A Comparative Law Perspective. London: Routledge, 2018.

SOMOVILLA, Claudia. La crisis habitacional y el acceso a la vivienda (19161930) -Intervencionismo estatal en los contratos de alquileres. Aequitas (Buenos Aires), año 8, vol. 8 (2014),

TAU ANZOATEGUI, Víctor [coord.]. Antología del pensamiento jurídico argentino (1901-1945), t. II. Buenos Aires: Instituto de Investigaciones de Historia del Derecho, 2008.

TORRES, Carlos Alberto. La universidad latinoamericana: de la reforma de 1918 al cambio estructural en los noventa. Revista Mexicana de Investigación Educativa, México, vol. 4, núm. 8 (julio-diciembre de 1999).

TRINDADE, Hélgio. A República em tempos de reforma: o desafio do governo Lula. Educaçao \& Sociedade (Campinas), vol. 25, núm 88 (octubre de 2004).

Recebido em: 01/10/2018.

Aprovado em: 13/11/2018. 